\title{
Effect of photoactive dye on bacteria contained in activated sludge
}

\author{
Miroslava Smolinskáa , Alžbeta Takáčováa, b \\ ${ }^{a}$ Department of Environmental Engineering, Institute of Chemical and Environmental Engineering, \\ Faculty of Chemical and Food Technology, Slovak University of Technology, \\ Radlinského 9, Bratislava 812 37, Slovak Republic \\ ${ }^{b}$ VÚRUP, a.s., Vlčie hrdlo, 82003 Bratislava, Slovak Republic \\ miroslava.smolinska@stuba.sk
}

\begin{abstract}
In this paper we focus on the evaluation of toxicity and phototoxicity of phenothiazine dye methylene blue on selected bacteria (Escherichia coli CCM 3988, Pseudomonas aeruginosa CCM 3955, Salmonella enterica ssp. Enterica serovar Enteritidis CCM 4420 and Bacillus subtilis CCM 1999), which are part of the activated sludge. The results obtained demonstrate that the induction of photodynamic effect is showed. Increased photoantibacterial activity may lead to inhibition of bacterial metabolic activity in the sludge. This effect may represent a potential risk to the ongoing processes in wastewater treatment.
\end{abstract}

Keywords: methylene blue, bacteria, photodynamic effect, activated sludge

\section{Introduction}

Coloured industrial wastewaters are the most common indicator of water pollution and pose a serious environmental risk (Wang et al. 2006). Dyes can absorb and reflect sunlight entering the water, absorb dissolved oxygen and thereby interfere with the growth of bacteria and thus inhibit photosynthesis in the aquatic environment (Bouasla et al. 2010, Jin et al. 2008). Reactive oxygen species generated by the absorption of light and subsequent photophysical processes of energy transfer in the presence of molecular oxygen can be toxic to the microbial population and can inhibit self-cleaning activity of microorganisms in wastewater. In addition, dyes exhibit in many cases toxic effects on microbial population formation of hazardous by-products through oxidation, hydrolysis or other chemical reactions (Idel-Aouad et al. 2011, Bouasla et al. 2010, Nakada et al. 2006). Bacteria that are part of the activated sludge are not able in the presence of these dyes to eliminate sufficient organic substances or nitrogen and phosphorus compounds from wastewater. Therefore, it is an important aspect to remove from industrial wastewater these dyes (Bouasla et al. 2010, Kuo and Ho 2001). The aim of this contribution was to evaluate the toxicity and phototoxicity of phenothiazine dye methylene blue on bacteria (Escherichia coli, Pseudomonas aeruginosa, Salmonella enterica ssp. Enterica serovar Enteritidis and Bacillus subtilis), which are part of the activated sludge.

\section{Materials and Methods}

Absorption spectrum of $\mathrm{MB}$ was measured at UV/ VIS spectrophotometer Specord 250 (Analytik Jena, Germany).
Spectrum of used lamp was measured with an optical fibre high resolution of Red Tide USB650 Fiber Optic Spectrometer (Ocean Optics, USA).

Formation of singlet oxygen was determined using EPR method. Suspensions of $2 \mathrm{ml}$ of TEMP solution $\left(10^{-5} \mathrm{~mol}^{-1} \mathrm{l}^{-1}\right)$ in chloroform were continually stirred in glass tubes and irradiated $\left(70 \mathrm{~W} \cdot \mathrm{m}^{-2}\right)$ by a $250 \mathrm{~W}$ halogen lamp through $5 \mathrm{~cm}$ water filter for $20 \mathrm{~min}$. The generated singlet oxygen was monitored indirectly by registration of an EPR signal from 2,2,6,6-tetramethylpiperidine-N-oxide (TEMPO) radical, which was formed by the reaction of TEMP with singlet oxygen. The first derivate EPR spectra of TEMPO were recorded at modulation amplitude $0.1 \mathrm{mT}$ and microwave power $5 \mathrm{~mW}$ in ERS-230 apparatus (ZWG, Germany).

Rate effect of methylene blue (MB, Sigma-Aldrich, USA) on bacterial growth was determined by a microdilution method which was carried out in micro-plates type P (GAMA, Czech Republic), 96-well plate. Toxicity tests were realized on the Gram-negative bacteria Escherichia coli CCM 3988, Pseudomonas aeruginosa CCM 3955 and Salmonella enterica ssp. Enterica serovar Enteritidis CCM 4420 and Gram-positive bacteria Bacillus subtilis CGM 1999 obtained from the Czech collection of microorganisms, Masaryk University, Brno, Czech Republic. Mueller-Hinton broth (MHB) was inoculated with over-night grown culture of bacteria (final cells density in MHB was $104 \mathrm{ml}^{-1}$ ). Experiments were carried out in two groups, the first group of samples was exposed to the light and the second group of samples was kept in the dark. Two control groups were prepared as follows: one by adding $200 \mu \mathrm{l} \mathrm{MHB}$ with cells of bacteria (2\% inoculum, positive control) and the second by mixing $150 \mu \mathrm{l}$ of 
MHB without bacteria and with $50 \mu \mathrm{l}$ of MB solution (background). Final concentrations of tested dye ranged from $0.37 \mu \mathrm{g} \cdot \mathrm{ml}^{-1}$ to $18.70 \mu \mathrm{g} \cdot \mathrm{ml}^{-1}$. $150 \mu \mathrm{l}$ MHB inoculated by bacteria was added to $50 \mu \mathrm{l}$ of MB solution at final concentrations ranging from $0.37 \mu \mathrm{g} \cdot \mathrm{ml}^{-1}$ to $18.70 \mu \mathrm{g} \cdot \mathrm{ml}^{-1}$. The light source emitting light in the visible region of the spectrum $\left(1.120 \mathrm{~mW} . \mathrm{cm}^{-2}\right)$ was placed vertically at a distance of $12 \mathrm{~cm}$ above the micro-plates. The bacteria were cultivated on a reciprocal shaker at $37^{\circ} \mathrm{C}$ for $8 \mathrm{~h}$ and one group of samples was constantly exposed to light. The growth of bacteria was quantified spectrophotometricaly by measuring absorbance at $630 \mathrm{~nm}$ at regular intervals, using ELx808 Absorbance Microplate Reader (Biotek, USA). The antimicrobial effect of MB was characterized by the $\mathrm{IC}_{50}$ and MIC values.

\section{Results and Discussion}

Spectral characterization of $\mathrm{MB}$ in aqueous solution is shown in Figure 1. Absorption spectrum of this dye overlaps with emission spectrum of our used LED system (not shown) that emits light in the visible spectrum $(600-670 \mathrm{~nm})$. The radiation flux density of this LED light system was 1.019 mW.cm ${ }^{-2}$. Radiometric measurement demonstrated $3.218 \times 1019$ photons $\cdot \mathrm{m}^{-2} \cdot \mathrm{s}^{-1}$. Therefore, the dye excited by light and subsequent photophysical processes of energy transfer in the presence of molecular oxygen could lead to the formation of reactive oxygen species.

This study evaluated the effect of MB after $8 \mathrm{~h}$ on the E. coli, P. aeruginosa, S. enterica and B. subtilis growth. Experiments were performed in the dark and in light conditions using LED system. Visible light alone had no effect on bacterial growth. It was found that the bacteria in the presence of MB have

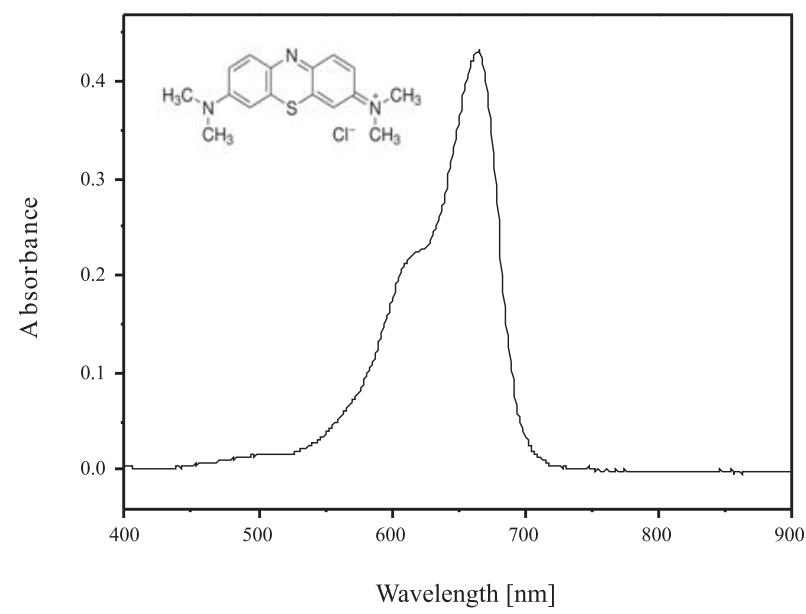

Fig. 1. Absorption spectrum of $10^{-5} \mathrm{M}$ methylene blue in aqueous solution. been inactivated in a particular amount as in the dark, as well as visible light. The degree of damage was dependent on the concentration of the dye. Differences between the two methods of cultivation, as well as between bacteria are shown in Figure 2 . Increasing the concentration of $\mathrm{MB}$ by influenced of visible light resulted in greater inhibition of $E$. coli growth for $8 \mathrm{~h}$ incubation in comparison with the darkness. Increased inhibition activity of MB light effects can be explained by the generation of reactive oxygen species, especially singlet oxygen (Figure 3), which can have such an inhibition effect (Wainwright and Crossley, 2002). In homogeneous solution MB produces triplets with high quantum yield $\left(\Phi_{\mathrm{T}}=0.52\right)$, working as a singlet oxygen photogenerated source $\left(\Phi_{\Delta} \sim 0.5\right)$ (Tardivo et al. 2005, Bonnet 2000). Percentage growth inhibition $P$. aeruginosa and S. enterica increased with increasing concentration of MB in the dark and light. However, visible light in the exponential growth phase did not increase the inhibition effect of the dye compared with darkness (Figure 2).

Singlet oxygen temporarily generated by irradiation was studied by the EPR spectroscopy. Figure 3 illustrates the EPR spectrum of MB recorded after irradiation of the system in the presence of TEMPO. This reaction product of singlet oxygen with TEMP is proven by the EPR spectra with the $g$ factor 2.0032 and the splitting constant $1.58 \mathrm{mT}$. It demonstrates that $\mathrm{MB}$ generates significant amounts of singlet oxygen.

Antibacterial and photoantibacterial effect of $\mathrm{MB}$ was evaluated by $\mathrm{MIC}$ and $\mathrm{IC}_{50}$ values (Table 1 ). Based on the results of microdilution method, we can conclude that the MB had the strongest inhibition effect on the growth of B. subtilis. $100 \%$ growth inhibition was observed at a concentration of $9.35 \mu \mathrm{g} . \mathrm{ml}^{-1}$ in samples cultured in the dark. The highest inhibition effect showed dye also on the growth of $B$. subtilis in experiments with light exposure, where MIC $=4.86 \mu \mathrm{g} \cdot \mathrm{ml}^{-1}$. From the MIC values can also be concluded that the growth of $E$. coli (MIC in the dark $=18.70 \mu \mathrm{g} \cdot \mathrm{ml}^{-1}$, MIC in the light $=13.09 \mu \mathrm{g} \cdot \mathrm{ml}^{-1}$ ) was less affected by MB compared to $B$. subtilis. The difference in susceptibility of bacteria on the effect of MB was observed in $P$. aeruginosa and $S$. enterica, which proved the lowest inhibition activity, which can be seen from the MIC values (Table 1).

Based on a comparison of growth inhibition $E$. coli, $P$. aeruginosa, S. enterica and B. subtilis in the presence of $\mathrm{MB}$ in the concentration range from 0.37 to $18.70 \mu \mathrm{g} \cdot \mathrm{ml}^{-1}$ and comparison of $\mathrm{IC}_{50}$ and MIC values, we can conclude that $P$. aeruginosa and $S$. enterica are least sensitive to the dye test (Figure 4). 

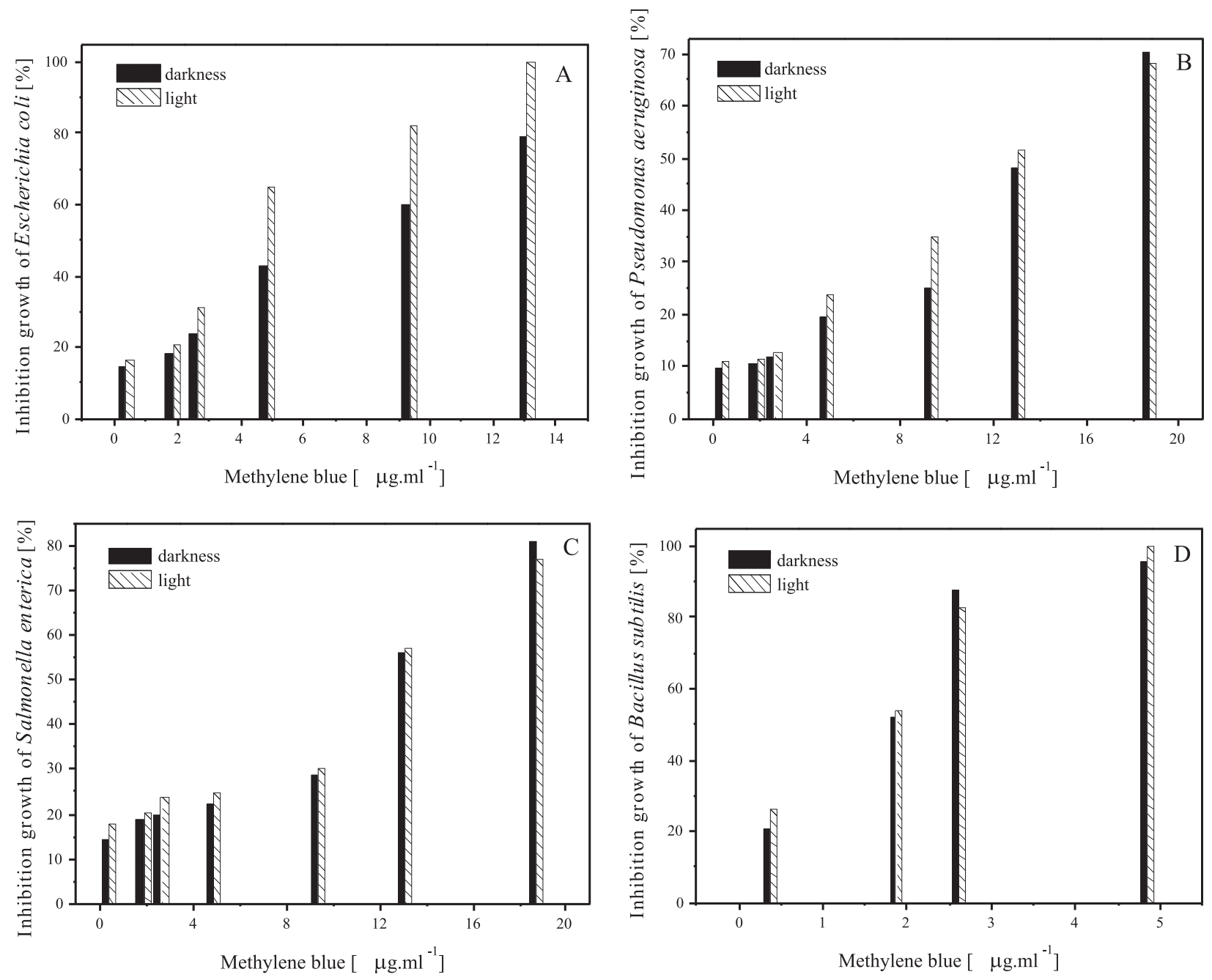

Fig. 2. The effect of visible light and different concentrations of methylene blue on E. coli (A), $P$. aeruginosa $(\mathrm{B})$, S. enterica $(\mathrm{C})$ and $B$. subtilis $(\mathrm{D})$. The bacteria were cultured with methylene blue in concentrations ranging from 0.37 to $18.70 \mu \mathrm{g} \cdot \mathrm{ml}^{-1}$. Effect in samples not exposed to the light source and the samples irradiated with visible light for $8 \mathrm{~h}$ was determined as percent inhibition.

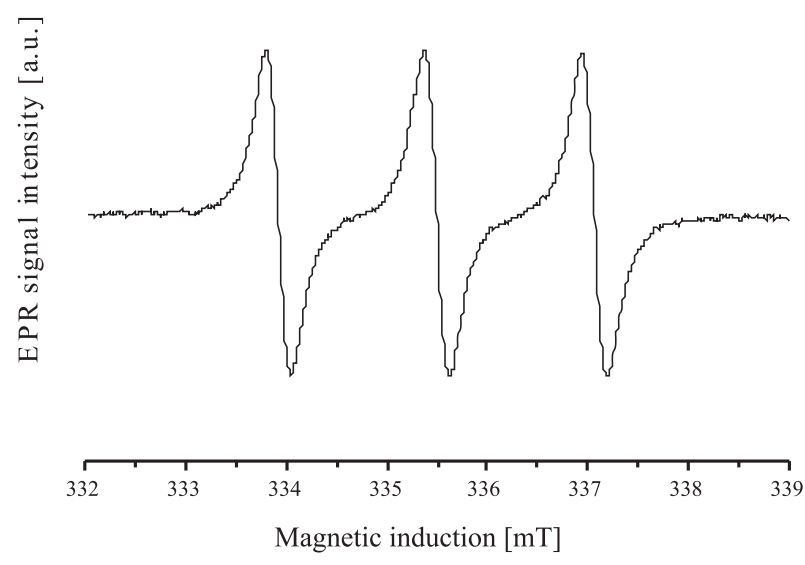

Fig. 3. EPR signal of TEMPO formed by the reaction of singlet oxygen with TEMP.
Our results show that $\mathrm{MB}$ is acting as photosensitizer and activated by visible light. Increased inhibition of this photoactive dye after irradiation can be explained by the generation of reactive oxygen species (Rolim et al. 2012, Wainwright and Crossley 2002, Benabbou et al. 2011). Photoantimicrobial lower activity of $\mathrm{MB}$ on the growth of $P$. aeruginosa and $S$. enterica could be related to the fact that at higher concentrations, MB may have to undergo a process of self-aggregation in aqueous media and as a result of this process can reduce the yield of singlet oxygen (Čeklovský et al. 2009). Aggregation causes a drastic reduction in the production of singlet oxygen, because the absorbed energy is released mostly through fast non-radiation processes (Lang et al. 2005). Furthermore, monomers and dimers MB may indicate photodynamic activity over type I photodynamic process, which is less active than type II mechanism (Usacheva et 
Tab. 1. Effect of methylene blue characterized by $\mathrm{IC}_{50}$ and MIC values.

\begin{tabular}{llcccc}
\hline$\mu \mathrm{g} . \mathrm{ml}^{-1}$ & & Escherichia coli & Pseudomonas aeruginosa & Salmonella enterica & Bacillus subtilis \\
\hline \multirow{2}{*}{ Darkness } & $\mathrm{IC}_{50}$ & 5.98 & 13.57 & 11.85 & 1.57 \\
& $\mathrm{MIC}$ & 18.70 & 37.39 & 37.39 & 9.35 \\
\multirow{2}{*}{ Light } & 3.89 & 12.64 & 11.63 & 1.12 \\
& $\mathrm{IC}_{50}$ & 37.39 & 37.39 & 4.86 \\
\hline
\end{tabular}

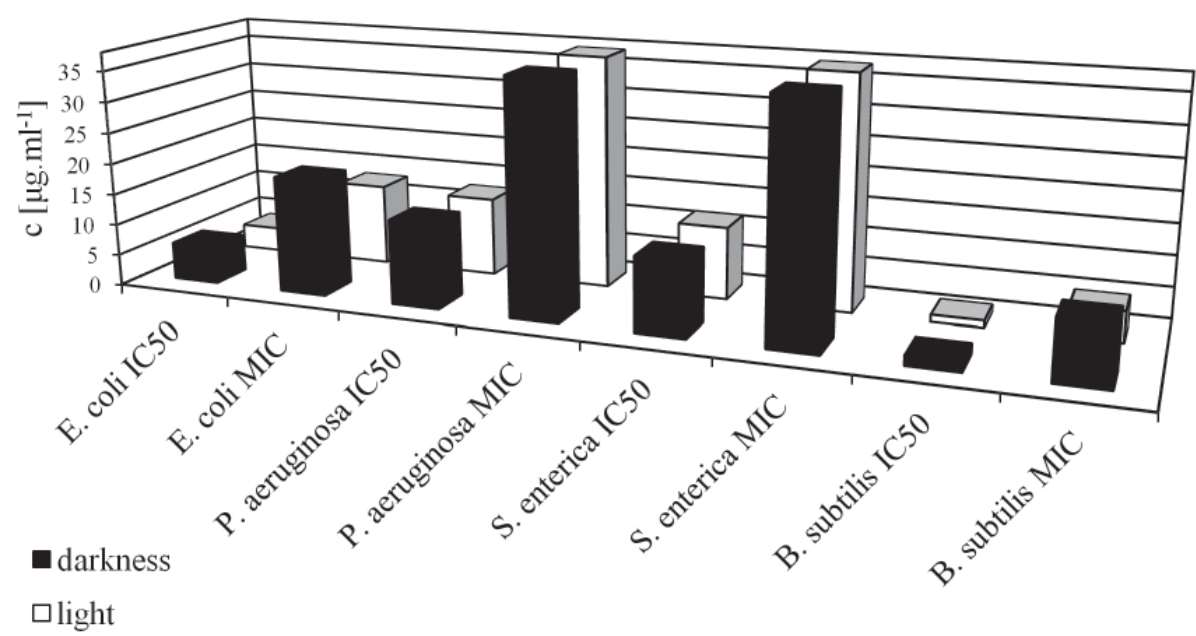

Fig. 4. Antibacterial activity of methylene blue characterized by $\mathrm{MIC}$ and $\mathrm{IC}_{50}$ values.

al. 2003). Based on the results obtained, we can also conclude that $B$. subtilis as a representative of Gram-positive bacteria is more sensitive to the dye test as E. coli, P. aeruginosa and S. enterica, representing Gram-negative bacteria. This difference can be related to the structure and composition of the cell walls affecting the adsorption of $\mathrm{MB}$ on the cell outer surface and/or the penetration and uptake of the dye inside the cells (Bujdák et al. 2009).

\section{Conclusion}

Methylene blue in the dark and in the light exposure showed a toxic effect on the growth of Escherichia coli, Pseudomonas aeruginosa, Salmonella enterica and Bacillus subtilis. Vitality of bacteria decreased depending on the concentration of the dye. Compared with the darkness, the influence of visible light to medium in combination with methylene blue increased percentage inhibition of E. coli and $B$. subtilis in the exponential growth phase. For $P$. aeruginosa and S. enterica were observed lower percent inhibition at exposure to light compared with darkness, resulting in lower MB photoeffect. Based on the comparison of MIC values was the highest growth photoinhibition in the presence of MB observed in B. subtilis ( $\mathrm{MIC}=4.86 \mu \mathrm{g} \cdot \mathrm{ml}^{-1}$ ). The lowest antibacterial activity showed MB on the growth of $P$. aeruginosa $\left(\mathrm{MIC}=37.39 \mu \mathrm{g} \cdot \mathrm{ml}^{-1}\right)$ and
S. enterica $\left(\mathrm{MIC}=37.39 \mu \mathrm{g} \cdot \mathrm{ml}^{-1}\right)$. MB significantly non-affected the bacterial growth of $P$. aeruginosa and S. enterica. In conclusion, it can be concluded that visible light increased the inhibition effect of $\mathrm{MB}$ in E. coli and B. subtilis during the exponential growth phase. This photoprocess can pose a risk to the environment. Enhanced antibacterial activity of MB due to visible light can lead to inhibition the metabolic activity of microorganisms in wastewater. For this reason, it is important to constantly develop new methods to reduce the toxicity of dyes present in the wastewater.

\section{References}

Benabbou AK, Guillard C, Pigeot-Rémy S, Cantau C, Pigot T, Lejeune P, Derriche Z, Lacombe S (2011) Journal of Photochemistry and Photobiology A: Chemistry 219: 101-108.

Bonnett R (2000) Chemical Aspects of Photodynamic Therapy, Gordon and Breach Science, Amsterdam.

Bouasla C, El-Hadi Samar M, Ismail F (2010) Desalination 254: 35-41.

Bujdák J, Jurečeková J, Bujdáková H, Lang K, Šeršeň F (2009) Environ. Sci. Technol. 43: 6202-6207.

Čeklovský A, Czímerová A, Lang K, Bujdák J (2009) Journal of Luminescence 129: 912-918.

Idel-Aouad R, Valiente M, Yaacoubi A, Tanouti B, LópezMesas M (2011) Journal of Hazardous Materials 186: $745-750$.

Jin X, Jiang M-q, Shan X-q, Pei Z-g, Chen Z (2008) Journal of Colloid and Interface Science 328: 243-247. 
Kuo WS, Ho PH (2001) Chemosphere 45: 77-83.

Lang K, Mosinger J, Wagnerová DM (2005) Chem. Listy 99: 211-221.

Nakada N, Tanishima T, Shinohara H, Kiri K, Takada H (2006) Water Research 40: 3297-3303.

Rolim JPML, de-Melo MAS, Guedes SF, AlbuquerqueFilho FB, de Souza JR, Nogueira NAP, Zanin ICJ, Rodrigues LKA (2012) Journal of Photochemistry and Photobiology B: Biology 106: 40-46.

Usacheva MN, Teichert MC, Biel MA (2003) Journal of Photochemistry and Photobiology B: Biology 71: 87-98.
Tardivo JP, Giglio A, Oliveira CS, Gabrielli DS, Junqueira HC, Tada DB, Severino D, Turchiello RF, Baptista MS (2005) Photodiagnosis and Photodynamic Therapy 2: 175-191.

Wainwright M, Crossley KB (2002) Journal of Chemotherapy 14: 431-443.

Wang S, Li H, Xu L (2006) Journal of Colloid and Interface Science 295: 71-78. 